Pak. j. sci. ind. res. Ser. A: phys. sci. 2018 61A(2) 84-90

\title{
Vibration Analysis of Cracked Composite Laminated Plate
}

\author{
Muhammad Imran*, Rafiullah Khan and Saeed Badshah \\ Department of Mechanical Engineering, International Islamic University, Islamabad, Pakistan
}

(received July 28, 2017; revised March 29, 2018; accepted March 30, 2018)

\begin{abstract}
An analysis of the free vibration response of the carbon fibre reinforced composite plate with delamination is presented here. The influence of the delamination size on the free vibration characteristics are studied. The composite material used is carbon fibre reinforced polymer with delamination at the middle of the plate. The experimental procedure consists of exciting the specimens with flexural modes for twelve modes for each delamination length. The effect of the delamination size was easily depicted by experiments by comparing the natural frequencies of laminated composite plate with and without delamination.
\end{abstract}

Keywords: carbon-fibre reinforced polymer, experimental model, delamination, composite plate.

\section{Introduction}

Composite structures have been widely used for various purposes ranging from simple laptop cases to complex high performance aircraft components, helicopter rotor blades, underwater hockey swim fins, boat hulls, swimming pools and bridges due to their stronger, lighter and up to date geometrics properties. The usage of carbon-fibre reinforced polymers (CFRP) have hugely increased due to lighter weight and high strength carbon fibres. CFRP have been used for light strength to weight ratios in aerospace engineering, automotive engineering, civil engineering and other applications and whenever high strength applications are considered. Cracks or delamination in composite plates are unavoidable during service period. There can be different parameters that effect its performance like service conditions, temperature or pressure variations. It has been experimentally validated that any specific delamination in a structure affects the dynamic performance of the whole structure. Moreover resonance or crack propagation within surface induce huge displacements or dislocations that leads to the structure failure. Because of their important applications, unique properties and widespread usage, the linear or non-linear criterion of these cracked/ delaminated structures, is to be investigated with great interest. Earlier, many numerical techniques were taken into consideration for predicting the behavior of vibrations in composite plates (Abbas et al., 2016).

Campanelli and Engblom (1995) compared the vibration analysis with modeling analysis for delaminated graphite/PEEK composite plates. Luo and Hanagud (1996) conducted experiments to find the vibration

*Author for correspondence;

E-mail: Muhammad.imran@iiu.edu.pk behaviour of glass fibre/epoxy composite plate with strip delamination. Hammami et al. (2016a) conducted experiments to find the linear and nonlinear vibration characteristics of composites with delamination. Jian et al. (1997) investigated the effect of circular delamination on thin unidirectional glass- fibre composite plates. Similar tests were also conducted by Kim et al. (2003); Kessler et al. (2002); Diaz Valdes and Soutis (1999); Paolozzi and Peroni, (1996) and Tenek et al. (1993). However, Penn et al. (1999) investigated through experiments that first six natural frequencies have very negligible influence of delamination presence. But the investigations done by Hou and Jeronimidis (1999) on circular composite plates concluded that significant increase in natural frequencies observed with an impact induced delamination. Experiments conducted by Hou and Jeronimidis 2000) found that increase in the bending stiffness values caused an increase in the frequency. Babu and Vasudevan (2017) conducted vibration analysis of tapered delaminated composite plate. Hirwani et al. (2016) conducted an experimental study to find the delamination effect on the vibration behaviour of woven glass/epoxy composite plate. Mohanty et al. (2012) conducted free vibration analysis of woven fibre glass/epoxy composite plate with delamination. For small delamination length, natural frequencies are less effected (Lou et al., 1997; Thornburgh and Chattopadhyay, 2002). Lee et al. (2003) investigated the effect of delamination length on multi-delaminated composite beam experimentally. Natural frequency decreased as the number of delamination increased. This finding was reported by Zhu et al. (2005) and Lee et al. (1995). Luo and Hanagud (2000) carried out experimental analysis on through-width delamination in composite beam. Experimental results were compared with Shen and 
Grady (1992). Hammai et al. (2016b) found the nonlinearity relation with delamination. Kumar and Shrivastava (2005) used thick square composite plate with rectangular cutout as reported by Reddy and Phan (1985). Azouaoui et al. (2007) investigated the delamination influence of glass/polyester composite plates. Krawczuk et al. (1997) studied the dynamics of cracked composite material structure. Chang et al. (1998) investigated the vibration analysis of composite plate with delamination under axial loads.

The review of the above experimental work highlighted the lack of studies on vibration analysis of delaminated composite plate using experimental techniques. The literature of experimental analysis on natural frequencies for carbon fibre reinforced polymer is very poor.

Therefore in the present study, free vibration of carbon reinforced polymers delaminated composite plate is investigated experimentally. The effect of other parameters like influence of delamination size, number of layers, ply orientation and boundary conditions on natural frequencies of carbon fibre reinforced polymer is largely studied.

\section{Materials and Methods}

The composite material presently studied is the carbon fibre reinforced polymer (CFRP) with unidirectional layers of epoxy and fibres matrix. The specimens are manufactured using handy layup method at room temperature. Teflon film is placed centrally at the mid span of the composite plate during manufacturing as shown in Fig. 1. Teflon layer is considered as delamination.

The delaminations have been incorporated at $5 \%$ to $75 \%$ with each $5 \%$ of CFRP plate. The natural frequencies of sixteen-layered carbon fibre composite plates with and without delamination have been determined experimentally using an accelerometer. The experimental configuration used is similar to earlier works (Hammami et al., 2016a; Idriss et al., 2015; Novak et al., 2012; Van Den Abeele et al., 2000). The specimens are tested for each delamination size. All tests performed are free vibration ones.

The dimensions of the carbon fibre reinforced polymer composite plate is $250 \mathrm{~mm} \times 250 \mathrm{~mm} \times 20 \mathrm{~mm}$. Thickness of each layer is $1.25 \mathrm{~mm}$ with 16 number of layers. Square size delamination was provided at the middle of the pate. $(0 / 45) 4 \mathrm{~s}$ and $(0 / 90) 4 \mathrm{~s}$ 16-layered were considered for the experimental study.

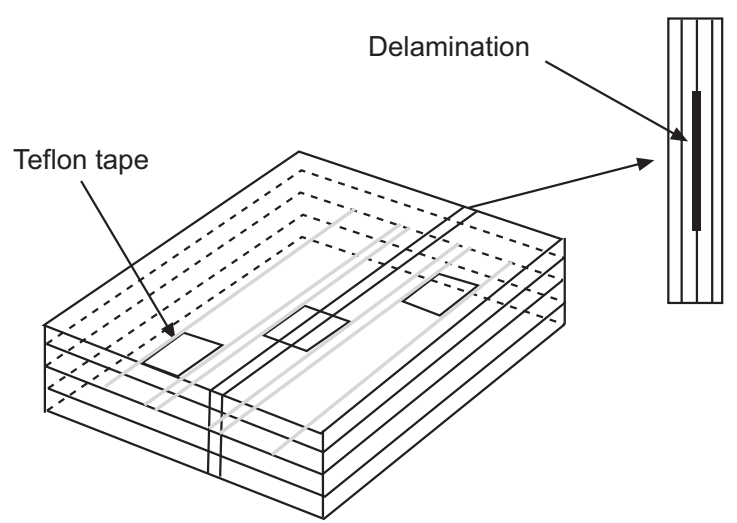

Fig. 1. Incorporation of Teflon tape for delamination (Lee et al., 2003)

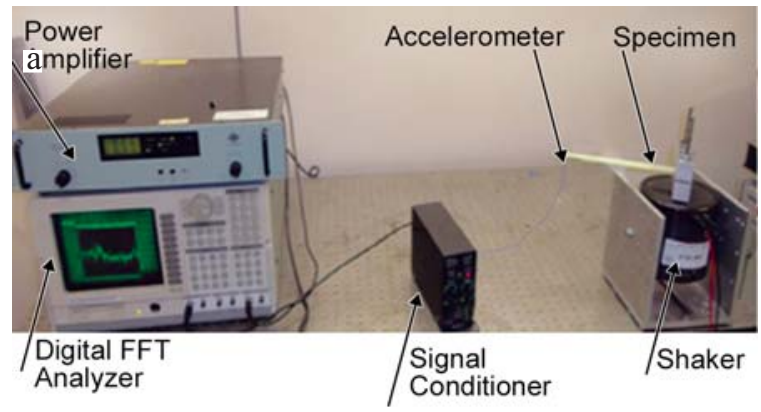

Data acquisition

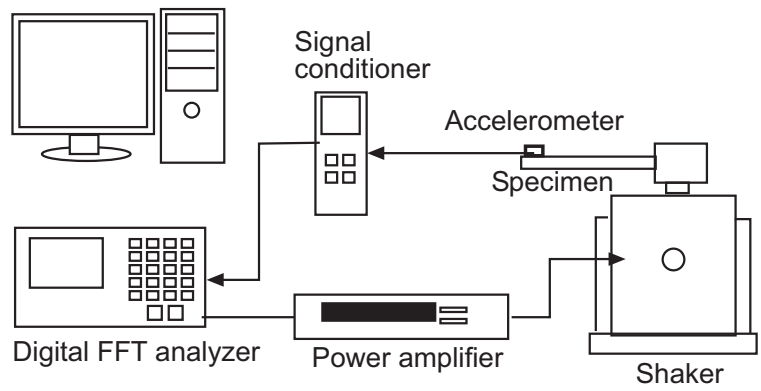

Fig. 2. Experimental setup for modal tests (Hammami et al., 2016a)

Following boundary conditions are considered for the experimental technique

F-F-F-F - Four edges free

S-S-S-S - Four edges simply supported

C-C-C-C - Four edges clamped

C-F-F-F - Cantilever supported

Finite element method FEM. For FEM analysis of the composite plate specified, ANSYS APDL was used for modelling, preprocessing, meshing, and solving. In 
ANSYS, it is not possible to easily simulate predelaminated regions using shell elements. For this composite plate, the thickness to length ratio is just over $10 \%$, so it is questionable whether or not shell elements will capture the true behaviour of the composite. For this simulation, solid elements were used with one element in the thickness direction for each prepeg layer. In order to properly simulate the fibre orientation for each laminate layer, custom coordinate systems were specified for each layer corresponding to the fibre orientation needed. For the simply supported constraint case, the bottom edges of the plate were constrained to have zero displacement in all cartesian axes. The different configurations of the plate simulated were as follows:

Stacking sequences

[0/90]

Delamination conditions

\section{$0 \%$ delamination}

$25 \%$ delamination

Each composite plate stacking sequence was simulated with every possible boundary condition and delamination condition. Therefore, 48 total simulations were performed corresponding to the possible configurations of the plate. Prepeg layers 1-3 and 5-8 were modelled using quadrilateral solid elements with an average size of 4 $\mathrm{mm}$. Layers four and five, were modelled using triangular solid elements with an average size of $4 \mathrm{~mm}$. The complete specifications of the mesh were as follows:

Total elements: 15,116

Total nodes: 76,649

Element aspect ratio

Maximum: 19.185; Minimum: 1.8351; Average: 2.838; Standard Deviation: 1.3095.

The orthotropic material properties of the carbon prepeg layers were as specified:

$$
\begin{aligned}
& \mathrm{E} 1=70 \mathrm{GPa} \\
& \mathrm{E} 2=70 \mathrm{GPa} \\
& \mathrm{G} 12=5 \mathrm{GPa} \\
& \nu=0.1 \text { (all directions) } \\
& \rho=1600 \frac{\mathrm{kg}}{\mathrm{m}^{3}}
\end{aligned}
$$

\section{Results and Discussion}

Experimental results for free vibration analysis of CFRP composite plates with delamination are presented in first section and in second section finite element analysis results are presented.

Effect of delamination size. For the experiments, it has been clear from Fig. 3 that the delamination size has significant impact on the natural frequencies of the

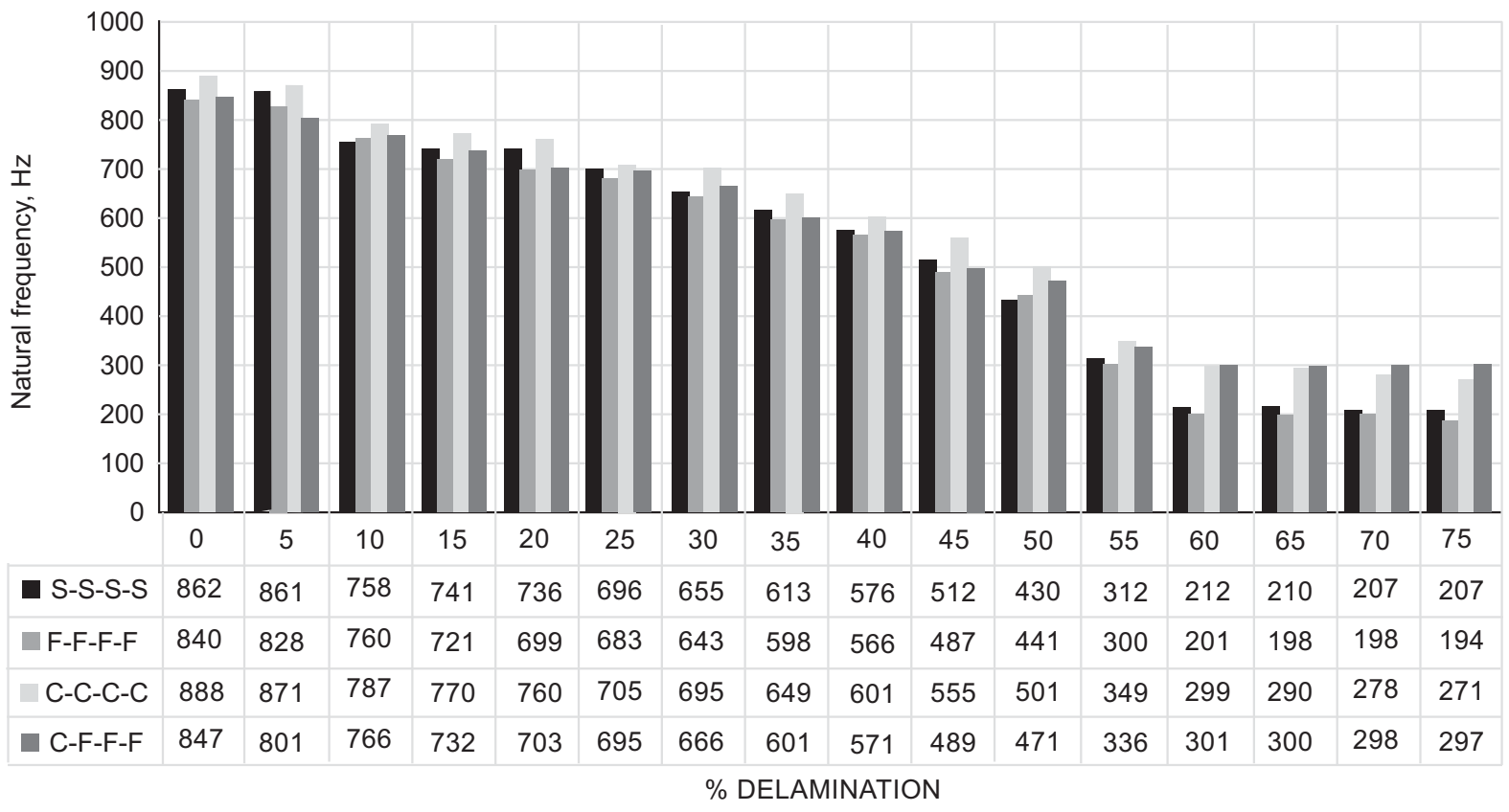

Fig. 3. Effect of delamination area for different boundary conditions with $(0 / 90)$ layup. 
delaminated composite plate. For all boundary conditions, fundamental natural frequencies decrease with an increase in delamination size for a layup configuration of (0/90), However, natural frequencies declining is consistent for the delamination of $60 \%$, $65 \%, 70 \%$ and $75 \%$. For high delamination area $(75 \%)$, the natural frequency is least affected for (0/90) layup method.

The same study was extended to (0/45) layup method as shown in Fig 4. For (0/45) layup configuration, cantilever plate has highest natural frequency than other configurations. Frequency drop for simply supported plate is less affected by delamination size as compared to the frequency drop of cantilever supported CFRP plate. For high delamination area, natural frequency is least affected for the simply supported plate. For low delamination area, four-sided clamped plates have highest natural frequencies. All sides' free constraints showed traditional response i.e., it declined rapidly initially and then steady decline was observed as the delamination length increased as shown in Fig. 4.

Effect of boundary conditions. The specimen taken for the analysis was of sixteen layered composite plate having stacking sequence of $(0 / 45) 4 \mathrm{~s}$ with $55 \%$ delaminated area.

The natural frequencies obtained at 55\% delamination area is presented in Table 1.

Least mode frequencies are observed for 1st, 2nd, 3rd, and 4th modes for F-F-F-F ( four side free), S-S-S-S (four sides simply supported) and C-F-F-F (Cantilever) boundary conditions and the highest natural frequency is observed for C-C-C-C (four sides clamped) boundary condition. These behaviours were also observed by Mohanty et al. (2012). Table 1 shows that natural frequencies are highly affected by boundary conditions.

Table 1. Natural frequencies of experimental results for $55 \%$ delaminated area for $(0 / 45)$ layup configuration

\begin{tabular}{lllllllllllll}
\hline \hline $\begin{array}{l}\text { Boundary } \\
\text { conditions }\end{array}$ & $1^{\text {st }}$ & $2^{\text {nd }}$ & $3^{\text {nd }}$ & $4^{\text {th }}$ & $5^{\text {th }}$ & $6^{\text {th }}$ & $7^{\text {th }}$ & $8^{\text {th }}$ & $9^{\text {th }}$ & $10^{\text {th }}$ & $11^{\text {th }}$ & $12^{\text {th }}$ \\
\hline F-F-F-F & 151 & 260 & 363 & 415 & 590 & 672 & 741 & 799 & 892 & 945 & 1005 & 1090 \\
S-S-S-S & 170 & 290 & 370 & 455 & 549 & 612 & 714 & 802 & 888 & 923 & 998 & 1150 \\
C-C-C-C & 191 & 316 & 498 & 578 & 689 & 776 & 879 & 942 & 1050 & 1189 & 1275 & 1356 \\
C-F-F-F & 80 & 175 & 250 & 326 & 446 & 501 & 589 & 634 & 701 & 775 & 816 & 848 \\
\hline \hline
\end{tabular}

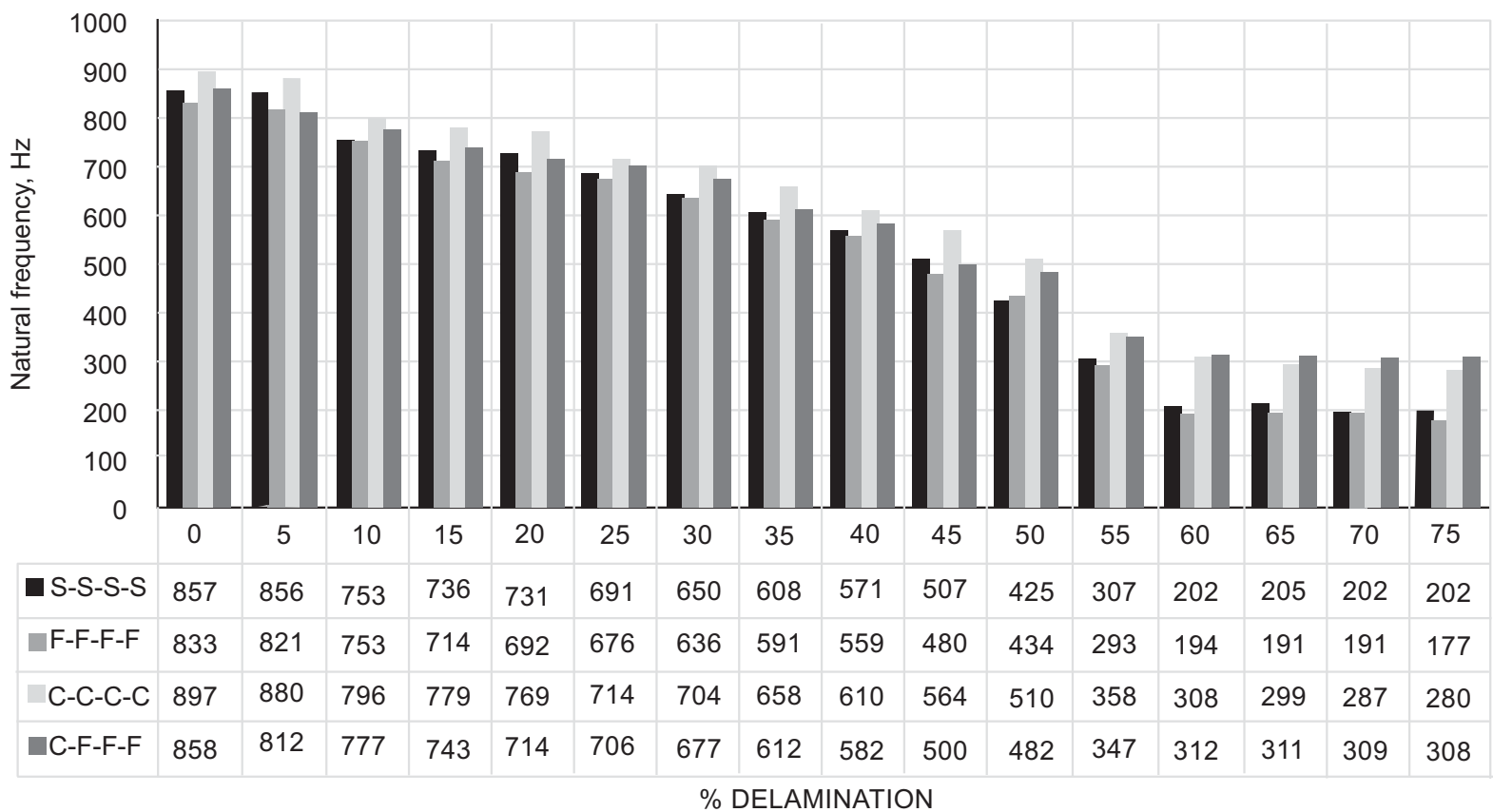

Fig. 4. Effect of delamination area for different boundary condition with (0/45) layup. 
Finite element results. The natural frequencies for each plate configuration were determined. Because the natural frequencies for the simply supported case and the free vibration case are extremely low, they have been separated from the clamped cases in order to show the effect of delamination size most effectively. Table 2 and Fig. 5 show data for boundary conditions CCCC \& CFFF.

Effect of delamination size. Interestingly, the size of the delaminated region had negligible effect on the average natural frequency for each mode shape for both of the clamped boundary conditions. The difference in natural frequency for each mode number is very small. This may be due to the physical effect of the clamped boundary condition. This effect seems to dominate the analysis, not allowing for the delaminated region size to have a sizeable impact. Conversely, for the free vibration and simply supported cases, the delaminated

Table 2. Average natural frequencies for CCCC \& CFFF using Finite element analysis

\begin{tabular}{lll}
\hline \hline Mode number & $0 \%$ & $25 \%$ \\
\hline 1 & 484.58 & 484.88 \\
2 & 983.01 & 982.67 \\
3 & 1172.69 & 1175.9 \\
4 & 1598.46 & 1604.18 \\
5 & 1969.09 & 1979.05 \\
6 & 2205.5 & 2206.31 \\
7 & 2724.95 & 2749.8 \\
8 & 2741.46 & 2764.95 \\
9 & 3347.73 & 3386.06 \\
10 & 3636.25 & 3649.73 \\
11 & 3698.216667 & 3696.266667 \\
12 & 4170.15 & 3970.8 \\
\hline \hline
\end{tabular}

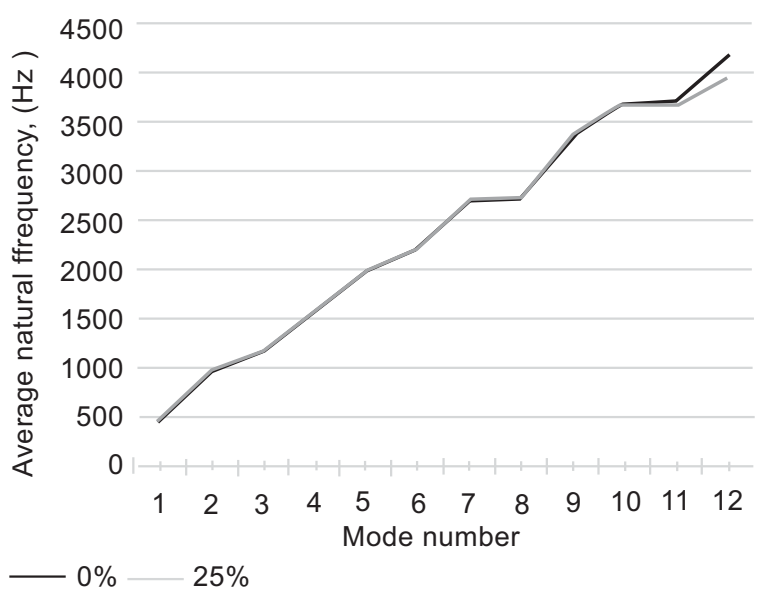

Fig. 5. Comparison of average natural frequencies for each delamination region size. region does have an impressive effect on the natural frequency for each mode. The minimum observed natural frequencies were for a delamination size of $25 \%$ as seen in Table 2

Effect of boundary conditions. The maximum natural frequencies observed with respect to boundary conditions belonged to the plates having clamped constraints on all sides. The next highest frequencies belonged to the plates having clamped constraints on one side. This makes logical sense, because vibrations in each mode are harder to achieve the more constrained the boundary conditions. For the simply supported and free vibration cases, the free vibration case had maximum natural frequencies between mode numbers 1-7 as shown in Table 3.

Table 3. Average natural frequencies for $\mathrm{CCCC}, \mathrm{FFFF}$, SSSS and CFFF boundary condition

\begin{tabular}{lllll}
\hline \hline Mode number & CCCC & FFFF & SSSS & CFFF \\
\hline 1 & 884.12 & 303.0 & 291.0 & 156.32 \\
2 & 1730.96 & 345.0 & 331.0 & 306.36 \\
3 & 1732.78 & 375.0 & 365.0 & 656.66 \\
4 & 2431.01 & 412.0 & 392.0 & 812.308 \\
5 & 2914.53 & 429.0 & 420.0 & 909.36 \\
6 & 3089.72 & 442.0 & 437.0 & 1330.46 \\
7 & 3518.50 & 456.0 & 451.0 & 1773.94 \\
8 & 3686.26 & 465.0 & 470.0 & 1801.70 \\
9 & 4431.66 & 473.0 & 486.0 & 2008.65 \\
10 & 4856.44 & 489.0 & 501.0 & 2347.98 \\
11 & 4953.73 & 504.0 & 510.0 & 2390.11 \\
12 & 5296.78 & 511.0 & 530.0 & 2752.2 \\
\hline \hline
\end{tabular}

\section{Conclusion}

In this research, influence of delamination size and boundary conditions, for carbon fibre reinforced composite plate, with delamination at the mid-plane are investigated. It is concluded by both experimentally and finite element methods that the natural frequencies decrease with an increase of delamination area. Effect of delamination depends on size of delamination and boundary conditions. For clamped-clamped boundary conditions, maximum natural frequencies observed for both finite element and experimental results.

\section{References}

Abbas, S., Abbas, Z., Pasha, R. A. 2016. Analytical estimation and numerical simulation of vibration based Piezoelectric energy harvesters. International 
Journal of Science, Engineering and Innovative Research, 13: 1-9.

Ananda Babu, A., Vasudevan, R. 2017. Vibration analysis of rotating delaminated non-uniform composite plates. Aerospace Science and Technology, 60: 172-182.

Azouaoui, K., Ouali, N., Ouroua, Y., Mesbah, A., Boukharouba, T. 2007. Damage characterisation of glass/polyester composite plates subjected to low-energy impact fatigue. Journal of Sound and Vibration, 308: 504-513.

Campanelli, R.W., Engblom, J.J. 1995. The effect of aminations in graphite/PEEK composite plates on modal dynamic characteristics. Composite Structures, 31: 195-202.

Chang, T.-P., Hu, C.-Y., Jane, K.-C. 1998. Vibration analysis of delaminated composite plates under axial load*. Journal of Mechanics of Structures and Machines, 26: 195-218.

Diaz Valdes, S. H., Soutis, C. 1999. Delamination detection in composite laminates from variations of their Modal Characteristics. Journal of Sound and Vibration, 228: 1-9.

Hammami, M., El Mahi, A., Karra, C., Haddar, M. 2016a. Experimental analysis of the linear and nonlinear behaviour of composites with delaminations. Applied Acoustics, 108: 31-39.

Hammami, M., El Mahi, A., Karra, C., Haddar, M. 2016b. Nonlinear behaviour of glass fibre reinforced composites with delamination. Composites Part B: Engineering, 92: 350-359.

Hirwani, C.K., Sahoo, S. S., Panda, S. K. 2016 Effect of delamination on vibration behaviour of woven glass/epoxy composite plate-An experimental study. IOP Conference Series: Materials Science and Engineering, vol. 115, No. 1. IOP Publishing, 2016.

Hou, J., Jeronimidis, G. 2000. Bending stiffness of composite plates with delamination. Composites Part A: Applied Science and Manufacturing, 31: 121-132.

Hou, J., Jeronimidis, G. 1999. Vibration of delaminated thin composite plates. Composites Part A: Applied Science and Manufacturing, 30: 989-995.

Idriss, M., El Mahi, A., El Guerjouma, R. 2015. Characterization of sandwich beams with debonding by linear and nonlinear vibration method. Composite Structures, 120: 200-207.

Jian, X., Tzou, H., Lissenden, C., Penn, L. 1997. Damage detection by piezoelectric patches in a free vibration method. Journal of Composite Materials, 31: 345-359.

Ju, F., Lee, H., Lee, K. 1995. Finite element analysis of free vibration of delaminated composite plates. Composites Engineering, 5: 195-209.

Kessler, S.S., Spearing, S. M., Atalla, M.J., Cesnik, C.E.S., Soutis, C. 2002. Damage detection in composite materials using frequency response methods. Composites Part B: Engineering, 33: $87-$ 95.

Kim, H.S., Chattopadhyay, A., Ghoshal, A. 2003. Dynamic analysis of composite laminates with multiple delamination using improved layerwise theory. AIAA Journal, 41: 1771-1779.

Krawczuk, M., Ostachowicz, W., Zak, A. 1997. Dynamics of cracked composite material structures. Computational Mechanics, 20: 79-83.

Kumar, A., Shrivastava, R. 2005. Free vibration of square laminates with delamination around a central cutout using HSDT. Composite Structures, 70: 317 333.

Lee, S., Park, T., Voyiadjis, G. Z. 2003. Vibration analysis of multi-delaminated beams. Composites Part B: Engineering, 34: 647-659.

Luo, H., Hanagud, S. 2000. Dynamics of delaminated beams. International Journal of Solids and Structures, 37: 1501-1519.

Luo, H., Hanagud, S., Luo, H., Hanagud, S. 1997. PVDF Sensor and its Applications in Delamination Response Detection. Paper presented at the $38^{\text {th }}$ Structures, Structural Dynamics, and Materials Conference.

Luo, H., Hanagud, S. 1996. Delamination modes in composite plates. Journal of Aerospace Engineering, 9: 106-113.

Mohanty, J., Sahu, S., Parhi, P. 2012. Numerical and experimental study on free vibration of delaminated woven fibre glass/epoxy composite plates. International Journal of Structural Stability and Dynamics, 12: 377-394.

Novak, A., Bentahar, M., Tournat, V., El Guerjouma, R., Simon, L. 2012. Nonlinear acoustic characterization of micro-damaged materials through higher harmonic resonance analysis. $N d t \& E$ International, 45: 1-8.

Paolozzi, A., Peroni, I. 1996. Experimental assessment of debonding damage in a carbon-fibre reinforced plastic sandwich panel by frequency variations. Composite Structures, 35: 435-444.

Penn, L., Jump, J., Greenfield, M., Blandford, G. 1999. 
Use of the free vibration spectrum to detect delamination in thick composites. Journal of Composite Materials, 33: 54-72.

Reddy, J. N., Phan, N. D. 1985. Stability and vibration of isotropic, orthotropic and laminated plates according to a higher-order shear deformation theory. Journal of Sound and Vibration, 98: 157-170.

Shen, M.-H., Grady, J. 1992. Free vibrations of delaminated beams. AIAA Journal, 30: 1361-1370.

Tenek, L. H., Henneke, E. G., Gunzburger, M. D. 1993. Vibration of delaminated composite plates and some applications to non-destructive testing. Composite Structures, 23: 253-262.

Thornburgh, R., Chattopadhyay, A. 2002. Modeling the
Dynamic Effects of Delamination in Adaptive Composite laminate. Paper presented at the $43^{\text {rd }}$ AIAA/ASME/ASCE/AHS/ASC Structures, Structural Dynamics, and Materials Conference.

Van Den Abeele, K.-A., Johnson, P. A., Sutin, A. 2000. Nonlinear elastic wave spectroscopy (NEWS) techniques to discern material damage, part I: nonlinear wave modulation spectroscopy (NWMS). Journal of Research in Nondestructive Evaluation, 12: 17-30.

Zhu, J.-F., Gu, Y., Tong, L. 2005. Formulation of reference surface element and its applications in dynamic analysis of delaminated composite beams. Composite Structures, 68: 481-490. 